\title{
The Contribution of Computer Science Education in a Creative Society
}

\author{
Ralf Romeike \\ University of Potsdam \\ Department of Computer Science \\ A.-Bebel-Str. 89 \\ 14482 Potsdam, Germany \\ romeike@cs.uni-potsdam.de
}

\begin{abstract}
This article builds on the assumption that learning to live in the knowledge society requires creativity; it points out how the school subject of computer science (CS) can contribute to that issue and presents results of a study concerning how students think about CS and creativity after experiencing creative programming. A strong connection between creativity and CS was described by the students. Diverse possibilities of how CS contributes to creativity, applies creativity and ways of how the students can include gained CS knowledge in order to be creative were explained. The results are discussed in the context of current research.
\end{abstract}

\section{Introduction}

It is not a new idea that we are educating our students for a "new" society which is greatly influenced by the increasing role of technology and the expanding growth of available information and knowledge. Since about the 1990s it is called the Knowledge Society. With its consideration comes a new perspective of learning: life long learning. Several educators are facing the issue and publishing ideas of how to cope with this challenge. Creativity seems to appear as a key factor in the discussion. In the position paper on life long learning of the International Federation on Information Processing (IFIP) the role of ICT is seen as "one of empowerment, enhancement of creativity and support" [1]. In the IFIP/Unesco ICT Curriculum for secondary schools creativity is considered in the "transforming approach" at the highest stage of school development [2]. Resnick [3] extends the picture of the knowledge society. He claims that knowledge alone is not enough. Rather, he suggests speaking about a Creative Society because "[i]n today's rapidly changing world, people must continually come up with creative solutions to unexpected problems. Success is based not 
only on what you know or how much you know, but on your ability to think and act creatively" ([3] p.1).

With CS exists a subject in schools that does not only make use of ICT but which has the creative use and design of technology in the centre of its focus ${ }^{1}$. Given that an understanding of the underlying principles and concepts of ICT is essential for its efficient use, CS can contribute a lot to the qualification and preparation of the students for everyday challenges and life long learning. Unfortunately CS curricula and the preconceived notions of CS in public do not necessarily reflect this creative view; CS often is perceived as technical, uncommunicative and uncreative. We investigated how this view can be changed when confronting an $11^{\text {th }}$ year high school class with a creative introduction to programming (cp. [4]). In the survey after the course a strong connection between creativity and CS was described by the students. Diverse possibilities of how CS contributes to creativity, applies creativity and ways of how they can include gained CS knowledge in order to be creative were explained.

\section{Creativity}

The term creativity is used with different meanings and is discussed controversially in psychology. Common speech usually defines something as creative when coming from the arts or something extraordinary. But not just artists can be creative. Everyday life requires creativity - and so does CS. There is agreement in psychology that something is creative if it is new, original and useful. Boden [5] describes two aspects of creative achievements. Historical creativity (h-creativity) describes ideas which are novel and original in the sense that nobody has had them before. Something that is fundamentally novel to the individual Boden describes as psychologically creative (p-creativity). In an educational context the latter is more interesting and can be aimed for in the classroom. In this paper we want to call something creative if it leads to personal new, unique and useful ideas, solutions or insights (cp. [6, 7]). As summarized by [8], in the classroom creativity can enhance learning through improved motivation, alertness, curiosity, concentration and achievement.

\section{The Contribution of CS to Creative Life Long Learning}

Creativity is a phenomenon of human behavior which is generally valued, admired and desired from politics and industry. As such the encouragement of creativity found its way into schools and curricula. Creativity is also aimed for as a superior learning objective in CS education. Keeping in mind the role of ICT in life long learning as enhancement and support of creativity, the subject of CS is in a fortunate position: Technology, software and skilled teachers are part of the learning environment in CS classrooms. Many of the specific tasks for creativity supporting software

${ }^{1}$ We refer in this paper to the school subject of computer science / informatics in German high schools. Topics include various aspects of CS, such as programming, practical, theoretical, technical and social aspects of CS. 
tools [9] are fulfilled by the software used in CS education. Furthermore CS concepts which are essential for the efficient, creative use and understanding of ICT are central to the subject. In addition the possibilities CS offers for working creatively can have a major impact on students' motivation and interest. These three drivers for creativity in CS education are explained in more detail in [10].

Nevertheless the possibilities that CS education offers for creativity are not well reflected in practice (e.g. [11-13]). As Resnick points out for schools in general, in CS "many students learn to solve specific types of problems, but they are unable to adapt and improvise in response to the unexpected situations that inevitably arise in today's fast-changing world" [3]. We see a reason for this in the character of assigned problem-solving tasks in CS education. The curriculum and the corresponding tasks which teachers assign within the CS classroom concentrate very much on solving specific tasks and problems. However, students have a hard time seeing problems themselves and find getting comfortable with new, unexpected situations difficult.

For us it seems to be important to disclose the creative potential of CS to the students. This can be done by actively engaging the students with tasks that require the application of creativity. This approach has been successfully applied, even if only by a few researchers. Some examples include after school clubs [14] and introductory college courses (e.g. $[15,16])$. In CS high school lessons, creativity still is hardly utilized [17].

For establishing a framework that helps designing creative CS lessons we proposed criteria for creative lessons. Applying these resulted in an improved perception which students have about CS and also improved achievements (cp. [4]). However, we also experienced that it is sometimes not easy to change a firm stereotype of CS, as illustrated by the following example. After the lessons one student seemed quite unhappy and uncertain. When she was asked about what was bothering her she answered that she found the lessons a bit strange and asked when we will start with "real" CS. The experienced lessons in her opinion have been so "c-r-e-a-t-i-v-e". In the students opinion other subjects are supposed to be creative - but not CS. Asked about if she understood the content and if she enjoyed the lessons she agreed. The lessons just had not met her pre-conceived notion of CS. Taking this students' dilemma into account we were wondering what the rest of the class thought about the creativity vs. CS dichotomy. What is their understanding of creativity? Do students think CS is creative? Will creativity help them in CS? Did the creative programming course help them to discover the creative possibilities of CS? Answers to these questions may help to situate creativity better into the learning process and lead students' actions towards a proper understanding of what the essence of CS is. Generalizing the results may encourage teachers of other subjects to consider creativity as well in their classes and thus better prepare the students for life long learning.

\section{Students' Perception and Understanding of Creativity in CS}

\subsection{Methodology}

The aforementioned questions were addressed by using a qualitative research approach. A quantitative approach using detailed questionnaires in the evaluation of the 
course revealed to us an abstract overview about the success of the creative teaching unit and changes of the students' perceptions of CS. However, the qualitative approach allows us to look behind standardized answers and to investigate the issues concerning creativity in CS in more detail. Data-collection consisted of brainstorming sessions and short essays written by the students. The objective of the study is to enhance understanding of how creativity is perceived by the students after being confronted with creative programming tasks but without bringing up the topic explicitly. The survey also built a starting point for an in-class discussion regarding what CS can do for creativity and vice versa.

\subsection{Data Collection and Analysis}

The survey was performed following a creative introduction to programming (cp. [4]). This was done in a German high school class with 21 students of whom 18 students (11 male, 7 female, ages 16 to 17 ) participated in the survey. The survey consisted of two open tasks:

1. A visual brainstorming task with the keywords "creativity" and "computer science" in the middle of a sheet of paper and the headline question: "What comes into your mind about the topic creativity and CS?" The students worked about 10 minutes on this task.

2. Secondly, a writing task was given: "Now summarize in your own words, what comes into your mind about creativity as related to CS. You may explain the results of your brainstorming or describe other aspects. You can use examples to illustrate your explanations. Start with describing what you understand of creativity." The students worked about 20 min on this task.

First, the brainstorming sketches were analyzed and categorized. Then specific ideas within the brainstorming sketches corresponding to the previously found categories were collated. In the next step the short essays were analyzed with content analysis techniques to better understand how students perceive the connection between CS and creativity. This enabled us to identify the dimensions of the phenomenon described in the answers. The Analysis led to the following results.

\subsection{Results}

\section{Analyzing the brainstorming sketches}

Almost all students initially see connecting ideas between creativity and CS. While most of the students drew connections between the two subjects, two students were looking at both separately. However, in the explanations in the second task these two students also described connecting characteristics.

The students' brainstorming task led to results which can be assigned to 3 categories: results associated to creativity, results associated to CS and results somewhere between the two. The most popular results of each category are summarized in table 1 . The resulting categories from the brainstorming session overlap in relation to how the question was understood. The analysis gives us a general idea about the students' experiences and interpretation of the question. The most frequently named ideas for creativity as well as CS are stereotypical: Half of the students mentioned 
"art" as representative for creativity and also half mentioned "computer" as typical for CS. Half of the students saw the connection between CS and creativity in "programming". The next named item in this category was the programming language Scratch. Also several other ways of practically working with the computer were named as connecting creativity and CS.

Table 1: Brainstorming about CS and creativity. Most popular answers/category.

\begin{tabular}{|l|c|l|c|l|c|}
\hline \multicolumn{2}{|l|}{ Creativity } & \multicolumn{2}{l}{ Connecting Items } & \multicolumn{2}{l|}{ Computer Science } \\
\hline art & 9 & programming & 9 & computer & 10 \\
\hline realizing ideas & 5 & Scratch & 6 & data & 3 \\
\hline coming up with ideas & 5 & Webpage development & 4 & logic & 3 \\
\hline create & 4 & Photoshop/photo processing & 3 & programming & 3 \\
\hline handicrafts & 3 & music editing/creating & 3 & school lesson & 2 \\
\hline & & $\begin{array}{l}\text { creative writing } \\
\text { (e.g. with Word) }\end{array}$ & 3 & $\begin{array}{l}\text { internet and } \\
\text { applications }\end{array}$ & 2 \\
\hline paint & 3 & computer games & 3 & information & 1 \\
\hline free possibilites & 2 & ideas & 3 & new ideas & 1 \\
\hline imaginative & 2 & internet & 2 & new technology & 1 \\
\hline human ability & 2 & e-mail writing & 2 & abstract & 1 \\
\hline music & &
\end{tabular}

\section{Analyzing the short essays}

All students describe items and activities that are connected to both; creativity and CS. While the analysis of the brainstorming items shows a quite homogeneous picture with answers corresponding to three categories, the analysis of the individual opinions in the short essays reveals a multidimensional perspective of how creativity and CS can be perceived. By their description of how the two are related the diverse student answers can be arranged in five main categories:

\section{CS is creative by its nature}

Many students mention that in their eyes creativity is a necessity for CS, e.g. because programming requires creativity: "Connecting the two topics I immediately thought of programming. There you need to involve your own ideas."

Related to this viewpoint is the perspective of seeing CS as a form of applied creativity. This is based on the product orientation in CS. This perspective also involves a personal standpoint where creativity is seen as self-realization and self-fulfilment in realizing ideas by creating things. Hereby CS is seen as a way of doing so: "In regard to CS I see that with every program new things are made."

For us it seems interesting, that the students here comply with the p-creative view of creativity, where it is important for them to come up with personally new ideas, regardless if someone else has had them before. In addition when engaging in programming the feeling of doing something creative is motivating to the students.

\section{CS provides creativity support}

"CS for me is fostering creativity because it is not only opening one door, it is opening several doors [with possibilities]. Everyone can do something with it." 
ICT can support creativity and the students are also aware of this. Furthermore they extend the view on the strategies and concepts they learn in CS lessons for using ICT efficiently and creatively. This perspective also includes the application of utilities which enable the students to express themselves creatively: "For example when writing an e-mail creativity can be very important: If you want to write a love letter to a person by e-mail and it shall be a special one, you really need to be creative." This can by the appropriate use of tools and methods.

\section{Art perspective of CS}

In this perspective the students identify procedures in the CS field that are comparable with art, e.g. when visualizing information: "For making problems and relations more demonstrative (clips, charts, diagrams) in CS creativity is applied."

This view finds its application in the many crossover domains like media-design or computer-graphics where both, CS knowledge and artistic expression are combined creatively.

\section{Holistic perspective}

In this perspective the impact of CS products in the society and its creative development are reflected. Here the personal aspect is out of focus, but the overall development is observed. "CS nowadays is everywhere. It is so powerful, this I consider as creative." "Creativity in CS is responsible for the technological progress." With respect to the creative misuse of technology (i.e. hacking) and the critical awareness of the technological progress, these are crucial perspectives CS educators also should consider in their lessons when encouraging the students to become critical thinkers.

\section{Focusing on the difference}

For a few students, it was important to underline the difference between creativity and CS. They see creativity as a superior human characteristic which they do not want to bind too close to CS: "Programming fosters creativity of the programmer, and creativity is essential to programming. CS needs creativity, but creativity does not need CS."

\section{Discussion}

Summarizing, the students' answers revealed several perspectives of creativity and CS. It is interesting to see that the students perceived their own activity in CS as creative. Taking into account that this is motivating to them, emphasizing this characteristic of CS can be taken as an opportunity for fostering motivation and interest in the field as well. The results of the study described here support findings where creativity was named as a major driver for very successful students getting deeply involved with CS in school and in their free time as well [18]. Also, in studies with open source programmers creativity related factors were named as the most pervasive drivers and responsible for project involvement [19]. Following up on the results of the course evaluation described in [4] which showed a drastic increase of motivation, interest fun and other positive factors we now know more about the circumstances surrounding increased motivation. 
Especially interesting are those student answers, where a development of the stereotype becomes visible: "Generally CS and creativity obey different laws. CS needs logic and mathematical structures while creativity generally breaks out of these. Creativity bursts laws and algorithms while CS is dominated by those. Nevertheless CS doesn't work without creativity. For writing new programs and code a creative spirit is needed."

However, not all students formulated their understanding of creativity this way. A few focused on the creative use of ICT only. The positive side is that these students also had discovered the creative use of ICT for themselves. Nevertheless, from a CS perspective there is more to this that they can discover. Every student has his own concept of creativity and thus the answers are very diverse. Indeed the diversity of the answers is what makes it so interesting for a CS educator as several approaches for a creative look at CS are revealed. As it is a main task of the school to broaden students' horizons, the different ideas and perspectives students have on this issue can be utilized. In the course described in this paper we encouraged group discussions on where creativity helps in CS and vice versa. The students shared and discussed their views and even came up with good examples for the points made.

Can there be too much creativity? Undeniably, fostering creativity in the classroom can be unexpected and confusing to students if they are not used to it. The student cited above who was uncomfortable experiencing CS so creatively explained her standpoint in the survey in more detail. She did not like that "In CS lessons creativity means that the task is so open that (1) you need to come up with your own ideas (e.g. Which game shall I realize?), (2) you need to think about how you can realize these ideas and (3) everybody has different results!" With these statements the student exactly described some of the key criteria which the course was built on. The discomfort obviously came from the unfamiliar situation where she was not exactly told which steps she has to take and from a lack of ideas. While most of the other students did not have problems with coming up with ideas, this was really bothering her. Before starting the following course on creative computer graphics, some creativity techniques were introduced and practiced. This time all students enjoyed open and creative tasks. With this enjoyment of creative computing and the gained insights into underlying principles CS lessons can make an important contribution to the students' preparation for life long learning.

\section{Conclusion}

The resulting attitude of the students towards creativity in connection with CS after implicitly engaging creatively with the subject is a very attractive one. It is a perception that encourages young people to involve themselves with ICT for fun and as seeing it as enriching their personal life. By engaging creatively with CS they also develop digital literacy and skills that are essential in the Creative Society. Furthermore if this picture is transferred to the parents, other students and finally to the society we believe the perception of CS as boring and technical etc. soon may become obsolete. Warnings about to less people caring for getting involved in IT related jobs would be a thing of the past. Of course computer scientists need to evaluate for 
themselves if this picture actually reflects their understanding of the nature of CS. For us it certainly does.

\section{References}

1. M. Kendall, B. Samways, and J. Wibe: Position Paper Lifelong Learning (L11) Version 1. International Federation for Information Processing (IFIP), Laxenburg (2002).

2. T. van Weert, and D. Tinsley: Information and Communication Technology in Secondary Education - A Curriculum for Schools. UNESCO, Paris (2000).

3. M. Resnick: Sowing the Seeds for a More Creative Society. In: Learning \& Leading with Technology, International Society for Technology in Education (ISTE) (2007).

4. R. Romeike: Applying Creativity in CS High School Education - Criteria, Teaching Example and Evaluation. In: 7th Baltic Sea Conference on Computing Education Research, Koli Calling, Koli (2008).

5. M.A. Boden: The Creative Mind: Myths \& Mechanisms. Basic Books, London (1990).

6. M.A. Runco, and I. Chand: Cognition and Creativity. Educational Psychology Review. 7(3), 243-267 (1995).

7. J. C. Kaufman, and R. J. Sternberg: Creativity. Change: The Magazine of Higher Learning. 39(4), 55-60 (2007).

8. D. Fasko: Education and Creativity. Creativity Research Journal. 13(3-4), 317-327 (2000).

9. B. Shneiderman: Creativity Support Tools. Commun. ACM. 45(10), 116-120 (2002).

10. R. Romeike: Three Drivers for Creativity in Computer Science Education. In: IFIPConference on "Informatics, Mathematics and ICT: a golden triangle", Boston, USA (2007).

11. R. Mittermeir: Informatik-Unterricht: Bastel-Unterricht, Eine Intellektuelle Herausforderung oder "Preparation for the Information-Age". Medienimpulse. 9/33, 4- 11 (2000).

12. R.B. Sweeney: Creativity in the Information Technology Curriculum Proposal. In: 4th Conf. on Information Technology Curriculum, pp. 139-141, Lafayette, Indiana, USA (2003).

13. M. Guzdial, and E. Soloway: Teaching the Nintendo Generation to Program. Commun. ACM. 45(4), 17-21 (2002).

14. M. Resnick: Rethinking Learning in the Digital Age. In: Kirkman, G., (ed.) The Global Information Technology Report: Readiness for the Networked World, pp. 32-37. Oxford University Press, Oxford (2002).

15. E. Sutinen, and J. Tarhio: Teaching to Identify Problems in a Creative Way. In: 31st Frontiers in Education Conference. IEEE Computer Society (2001).

16. G. Lewandowski, E. Johnson, and M. Goldweber: Fostering a Creative Interest in Computer Science. In: SIGCSE '05, St. Louis, MO (2005).

17. R. Romeike: Kriterien Kreativen Informatikunterrichts. In: 12. GI-Fachtagung "Informatik und Schule - INFOS 2007". Köllen, Siegen, Germany (2007).

18. R. Romeike: Creative Students - What Can We Learn from Them for Teaching Computer Science? In: the 6th Baltic Sea Conference on Computing Education Research, Koli Calling. Uppsala University, Uppsala, Sweden (2006).

19. K. Lakhani, and R. Wolf: Why Hackers Do What They Do: Understanding Motivation Effort in Free/Open Source Software Projects. In: J. Feller, B. Fitzgerald, S. Hissam, and K. R. Lakhani (eds.) Perspectives on Free and Open Source Software, pp. 3-22. MIT Press (2005). 